\title{
'Notes on a Scandal': Why do Females Engage in Abuse of Trust Behaviours?
}

\author{
Andrea J. Darling* and Georgios A. Antonopoulos
}

\author{
School of Social Sciences and Law, Teesside University, Middlesbrough, TS1 3BA, UK
}

\begin{abstract}
Although an evident reality in organisations where females work with young people, there has been no specific research to date exploring why females in positions of trust engage in sexually abusive relationships with adolescents. This study investigated the subject through a qualitative analysis of ten case studies from England drawn from the employment and safeguarding environment, comparing findings with existing studies into female sexual offenders in general, research into male 'professional perpetrators' and Gannon et al.'s (2008) Descriptive Model of Female Sexual Offending. The research highlighted a number of key similarities and differences between those who abuse in positions of trust and those female sexual offenders who abuse children in wider contexts. With respect to etiological factors the similarities included unstable lifestyle, relationship difficulties, low self-esteem, cognitive distortions and emotional self-management problems. Motivations for this sample appeared to be primarily driven by intimacy needs. Differences were identified relating to lower levels of substance abuse, a higher age range and socio-economic status, less prevalence of severe social skills deficits and chaotic and abusive backgrounds in this subject group. All of the women in the study followed an Implicit Disorganised pathway of abuse and maternal approach to the abusive behaviour.
\end{abstract}

Keywords: Abuse of trust, female offenders.

\section{INTRODUCTION}

There is no known research specifically into females who engage in abuse of trust behaviours and related quantitative data is also scarce; yet this is an existing problem in organisational environments where women are responsible for the teaching or care of adolescents. This research explored a number of cases where females have engaged in abuse of trust behaviours in England to determine if there are common factors contributing to the abuse or similarities in patterns of behaviour that would enhance understanding of and help prevent future abuse of this type. Identified etiological factors in this sub-group were compared with existing theoretical frameworks and findings about female sex offenders, female child sex offenders in general and male professional perpetrators.

The term female child sexual abuser (FCSA) is used throughout this article as only one of the subjects in the case studies examined is a convicted offender. The abbreviation FCSO is used for female child sexual offender, referring to convicted offenders (or those with police cautions) and FSO for female sexual offender (including those who offend against adults). Likewise male child sex offenders are abbreviated to MCSOs and general male sex offenders to MSOs. 'Professional Perpetrator' is also used to describe those who use either their institutions or organisations within which

*Address correspondence to these authors at the School of Social Sciences and Law, Teesside University, Middlesbrough, TS1 3BA, UK; Tel: +44 (0) 1642 342392; E-mails: andreajdarling@hotmail.com, G.Antonopoulos@tees.ac.uk they work to target and abuse children (Sullivan et al., 2002).

'Abuse of Trust' offences first entered English and Welsh law with the Sexual Offences (Amendment) Act 2000. This piece of legislation sought to address cases where young people were over the age of legal consent for sexual activity but where it was felt that some individuals exploited their position of power over the young person in order to enter into sexual activity with them. Broadly, adults are considered in a 'position of trust' if they regularly look after, care for, train or supervise young people, so the offence covers a large range of professions including, teachers, some medical staff, youth workers, care home staff, foster carers etc. The Government's guidance on abuse of positions of trust explains that:

A sexual relationship itself will be intrinsically unequal within a relationship of trust and is therefore unacceptable. It is also inappropriate since the 'professional' relationship of trust would be altered.... The sexual activity covered by abuse of trust may be ostensibly consensual, but rendered unacceptable because of the relative positions of the parties concerned. This can be seen as undermining the ability of the individual being looked after to give free consent (Home Office, 2003: 5).

Female sexual offending against children is not a new phenomenon, however, compared to the interest 
in the offending perpetrated by males it has been rather neglected. That said, exposure around females who engage in sexual relationships whilst in positions of trust has increased over recent years via high profile media attention as well as dramatisation in films, and books. Despite a gradually increasing number of worthy studies into female sexual offending, the empirical research base remains relatively sparse. A number of years ago Grubin (1998) suggested that it was difficult to justify a shift of emphasis and resources away from research into male sex offenders, argued to be a much larger problem. This is a problematic view for a number of reasons, not least because regardless of the perceived comparative size of the problem, there is evidence that suggests that more serious, long-term harm for victims results from sexual abuse by women as opposed to men (see, for example, Saradjian, 2010; Denov, 2004a). Even with conservative estimates of the prevalence of such abuse, the number of victims is notable and high. However, assessing the true prevalence of female perpetrated child sexual abuse, and specifically that which occurs in the employment context, is problematic for a number of reasons: problems in defining 'child abuse' and the consequent differing applications in research studies and recording systems; data does not always reflect sufficient detail to isolate the age of the victim or the context in which the abuse occurred; and furthermore there is a perceived problem of significant under-reporting of this type of abuse partly due to victim disclosure reluctance exacerbated by the responses of professionals.

Estimates of the actual number of females who sexually offend against children vary over the years of research and are dependent on the view of the researcher/author. Research based on population studies show much higher levels of alleged abuse than official statistics suggest. The Lucy Faithfull Foundation, a UK child protection charity, estimates that up to $20 \%$ of suspected paedophiles in the UK are women (Townsend and Syal, 2009). More conservative estimates suggest that females account for $5-10 \%$ of all sexual abuse against children (Freel, 1998; Bunting, 2005; Gannon and Cortoni, 2010). Interestingly, and somewhat worryingly, these estimates are far removed from the official data reflective of what is happening in the criminal justice system. According to official government statistics, between 2001 and 2012 1.27\% of all child sex offences (cautions and convictions) were committed by females (Home Office, FOI Request June 2013). Further data in relation to female sexual offenders in the criminal justice system is not broken down into those who have offended against children and those who have offended against adults. However, for illustrative purposes, between April 2010 and June 2011 , only 47 FSOs were received into prison compared to 7,698 MSO's in the same period. At the end of June 201156 FSOs were being supervised by Probation compared to 2,376 MSO's. In total, this equates to just over $150 \mathrm{FSOs}$ in prison or under Probation in England and Wales compared to over 10,000 MSOs, equalling $1.5 \%$ (Ministry of Justice, 2011). The data relating to abuse of trust offences specifically show that between 2001 and 2012 they constituted $16.5 \%$ of all child sex offences committed by females compared to $1.23 \%$ of child sex offences committed by males. In the same period $11 \%$ of those convicted of, and $20 \%$ of those cautioned for, an abuse of trust offence were female (Ministry of Justice, FOI Request 26 June 2013).

Although from the data above the number of FSOs may appear low in comparison to MSOs the number of female offenders still equates to a potentially large number of victims and there is a widespread belief that child sexual offences perpetrated by women are significantly under-reported and taken less seriously by professionals than those perpetrated by males (see Bunting, 2005; Saradjian, 2010; Denov, 2004). Studies have shown that FSOs are (1) less likely to be arrested and convicted; and (2) more likely to receive lighter sentences and gender has been more influential in sentencing decisions than 'race', age or ethnicity (Sander and Freeman 2011). This may be influenced by a paternal or stereotypical view of women by those involved in the criminal justice system (Bunting, 2005; Denov, 2004). However, Sandler and Freeman (2011) also refer to other studies which have shown that the converse can be true where the offences go against the traditional gender expectations and that FSOs are sometimes treated more harshly than male equivalents.

Figures from an NSPCC (National Society for the Prevention of Cruelty to Children) report show there was an increase of 132 per cent in the number of children counselled by ChildLine in respect of sexual abuse by a female between 2004 and 2009 (NSPCC, 2010). In the same period 779 allegations of sexual abuse by a person in a position of trust were made (teachers, authority figures, foster parents) accounting for $6 \%$ of calls about sexual abuse, however, there is no specific breakdown of the sex of the abuser to determine the rate of female abuse in positions of trust.

Further research by the NSPCC (2011), via a nationally representative random probability sample of 
parents, children and young people in the UK, found that $5.3 \%$ of those victims reporting maltreatment by non-resident adults reported sexual abuse (these included for the most part adults in positions of trust e.g. teachers, babysitters, youth leaders, child minders, au pairs, adult workers with children but also included neighbours and family friends). $0.9 \%$ reported contact sexual abuse by a childminder, babysitter, au pair or an adult from an organisation such as a teacher, coach or youth leader. Unfortunately, no data is available to determine how many females were involved in these rates of alleged abuse.

\section{FEMALE SEXUAL ABUSERS OF CHILDREN IN THE WORKPLACE}

Although data availability makes it difficult to determine true rates, estimates suggest that $5-31 \%$ of sexual abuse against children is perpetrated in an organisational setting, primarily whilst babysitting, but also including abuse by nurses, teachers, scout leaders, foster parents and the clergy (Hunt, 2006). Referring to Freel's (2003) research, Erooga (2009) states that the results of self-administered questionnaires from public sector childcare workers in a UK local authority showed that $4 \%$ of the female respondents expressed a sexual interest in children and that $2 \%$ of the women admitted that they might have sex with a child "if it was certain no one would find out and there would be no punishment" (Erooga, 2009: 5). Babysitters and day care providers appear to be the most prolific of females who abuse in 'organisational settings' with teachers featuring as one of the next most frequent (Kaufman et al., 1995; Rudin et al., 1995; Whetsell-Mitchell and Morse, 1998; Elliot, 1994; Hunt, 2006; see also NSPCC 2011). With respect to 'abuse of trust' behaviours, true rates are even more difficult to accurately estimate. Problems with systematic mechanisms for recording and collating abuse cases nationally by organisations, authorities, police and criminal justice systems, the extremely limited research into the area, the potential for significant under-reporting and the only fairly recent introduction of the 'abuse of trust' offence all compound the difficulty determining the extent of this specific type of abuse.

\section{Culture of Denial}

Although attention has been drawn to female perpetrated child sexual abuse in recent years there has been an apparent reluctance on behalf of the public and professionals to date to accept the reality that women can and do sexually abuse. The social construction of women and sexual role stereotypes are considered to play a significant role in this culture of denial and the under-reporting of this type of abuse (Saradjian, 2010; Denov, 2004b). Views that sexual abuse by a female is less harmful, that women who do it are psychologically damaged and not in control of their own behaviour or coerced by male partners are held not only by the public but also by professionals with contact with children. Research has shown that the responses of professionals dealing with victims demonstrate gender bias and an increased likelihood to consider female child sex offenders more leniently than male offenders (Denov, 2004b; Bunting, 2005; Hetherton and Beardsall, 1998; Mellor and Deering, 2010; Kite and Tyson, 2004). Gartner (2005) also argues that currently there are double standards in society about adult-child sexuality resulting from gender myths and biases. This is particularly relevant to 'abuse of trust' relationships; how we look at male children being involved with sexual activity with female adults is very different to how we look at the situation when there is a female child and male adult involved.

\section{'Professional Perpetrators'}

It is clear from the existing literature that much research tends to focus on, or demonstrates much higher numbers of females who sexually abuse in domestic settings against their own children. There is little specific research into females who sexually abuse children or young people in the course of their profession (Sullivan et al., 2002). Yet, according to Faller, child care provision is the second most common context for FCSO (Faller cited in Brayford, 2012). Sullivan et al. (2002) conducted research into 'Professional perpetrators'; those who use either their institutions or organisations within which they work to target and abuse children. Although their results are of interest in this study given it is one of the few studies into professional perpetrators, they offer limited ability for comprehensive comparison with this research project given there were no females in their sample and no detail is provided in their reports as to the age of the victims involved.

Previous research into why females sexually abuse children has focused on socio-demographic features of perpetrators and victims and the generation of typologies rather than investigating treatment requirements and offence chain processes to truly address the etiology of female child sexual abuse (Gannon et al. 2008). This also exposes a real deficit in 
overall understanding about why sexual abuse by females in positions of trust occurs.

\section{Etiological Factors}

Although existing studies have been helpful in understanding more about individual or specific samples of FCSOs, there are a number or areas where findings are contradictory. These include differing results about the presence of psychiatric impairment and substance abuse problems; rates of lone offending and co-offending; the severity of the abuse and use of violence and victim gender selection (Hunt, 2006). Nonetheless, the findings in the existing research literature do tend to agree on a number of common characteristics of FSOs: that most are aged between 16 and 36 years old; most fall into low and middle range in terms of socio-economic status; many lack social skills, have low self-esteem and experience difficulty in relationships (Brayford, 2012). On initial consideration such characteristics are not those which might normally associated with professional perpetrators, such as those considered in this study, a number of whom were well qualified, successful teachers with positive social reputations and seemingly appropriate adult relationships.

Gannon et al. (2008) also proposed a number of vulnerability factors evident in females who have abused children: mental health problems; cognitions and empathy; deviant sexual interest; intimacy and social deficits; dependency issues and emotional selfmanagement problems. Sullivan et als studies (2004; 2010) compared male professional perpetrators to intra-familial and other extra-familial child sexual abusers. Their research showed that 93\% of professionals were aware of their sexual arousal to children by the time they were 21 years old (two thirds having committed a contact sexual offence against a child before that age) and 58\% reported that their motivation to enter their profession was influenced by the opportunity to gain access to children. Sullivan et al. $(2004 ; 2010)$ found that in comparison to other groups of sexual abusers, professional perpetrators had higher IQs, were older and were also less likely to be in adult sexual relationships or have children of their own. $51 \%$ were sexually abused themselves as children, which is comparable to the general population of MCSOs. Professional perpetrators were three times more likely to offend against post-pubescent children and had significantly higher levels of reported sexual pre-occupation and emotional over-identification with children as well as significantly lower levels of distorted sexual attitudes about their victims. In comparison to other groups professionals had the least problematic personal experiences in their own backgrounds (e.g. child abuse or substance abuse) and less previous convictions for both sexual and non-sexual offences. They also had significantly higher levels of victim blaming attitudes than the other groups but along with the intra-familial offenders, professionals held less empathy distortions than the extra-familial abusers.

FCSO perpetrated abuse may well be significantly under-reported, yet it is viewed by some to have a more serious longer term impact on the victims. Cultural and social norms do appear to impact on the recognition and reporting of this type of abuse and influence the treatment of female sexual offenders and victims throughout criminal justice and child protection systems. Ultimately, female perpetrated sexual abuse of children and young people in organisational settings is a reality and although lower in prevalence than male perpetrated abuse for all victim age groups, with regard to 16-17 year old adolescents proportionally more FCSOs are convicted of or cautioned for specific abuse of trust offences than MCSOs. No previous studies appear to have looked specifically at abuse against adolescents in the workplace and actions to address the problem of organisational sexual abuse have primarily concentrated on imposing external controls on abusers while neglecting options to better understand the characteristics of this specific type of abuser and the nature of their behaviour (Sullivan et al., 2002).

Previous FSO/FCSO studies have tended to focus on convicted offenders and have been biased towards mothers who sexually abuse their own (usually young) children. They have primarily involved forensic or clinical samples (Gannon et al., 2008) with limited data drawn from the employment/safeguarding arena which provides a wider range of backgrounds. Many have relied primarily on victims and observers reflections (only a few have attempted to learn from the perpetrators themselves) and no studies appear have focused exclusively on those women who abuse adolescents. Furthermore, it remains to be seen whether cases involving FCSO abuse of female adolescents differ to those of abuse of male adolescents as this does not appear to have been addressed in previous studies. Finally, in terms of theoretical frameworks, the sole existing model describing FCSO offending pathways (Gannon et als Descriptive Model of Female Sexual Offending) was developed on a sample acknowledged to be underrepresentative of females who worked alone against 
children (including 'teacher-lover' types: Mathews et al., 1989; Gannon et al., 2008). Therefore, our study helped to 'test' in a sense the validity of the model in relation to this specific category of abuser.

\section{METHODOLOGY}

Our study consisted of a qualitative analysis of the case files of ten females considered by employment safeguarding schemes in England and Wales between 2008 and 2013 following their involvement in sexual activity with children whilst in a position of trust. None were involved in co-offending. Eight were teachers, one was a foster carer and one was a learning assistant/ mentor. Only one had been convicted of a sexual offence (abuse of trust: sexual activity with a child). Seven had been referred to police or social services but not ultimately cautioned or convicted for an offence. Nine were involved in the abuse of only one victim ( 3 female and 6 male), one is known to have abused four victims (all male). Their ages at the time of the abusive behaviour ranged from 26 to 44 (mean= 35 ).

Convenience sampling was used to identify suitable case studies due to the availability of case files, the time available to locate files and the suitability for the research purposes. Critical characteristics were defined as being the necessity to meet the strict abuse of trust offence criteria (i.e. victim age, legal 'position of trust' post) and the sufficiency of useful credible data on the case files. The final sample was selected to reflect a cross-section of: perpetrator age and profession; gender of victim; whether or not a conviction or caution resulted or alternatively where allegations were substantiated. Although the sample did not result in findings that can be broadly generalised to the wider FCSA population, it allowed the development of logical generalisations from the rich evidence produced from studying those few cases in depth.

Systematic qualitative content analysis was employed to analyse the documents contained in the case files. Interpretation of case study documents was predominantly a mix of interpretative and direct coding. Common themes in the documents were identified and interpretative codes were assigned to assist the analysis. Themes and codes were identified from common features considered to be of etiological significance in previous FCSO research. These were expanded upon through the addition of potential factors derived from the first author's own professional experience of reviewing a significant number of cases involving abuse in positions of trust as well as through the identification of other potential factors arising in the cases themselves during the research process.

In analysing secondary sources such as witness statements, reports of events and so on much of what the abuser may be doing or the true motivations for this were not explicit and using this method helped to uncover and record hidden meanings and explanations. The limitations of interpretation are acknowledged in that the method is open to potential researcher bias or misinterpretation. There is also the possibility of the inability to be able to verify all interpretations. Moreover, responses given by FCSAs when dealing with others in their cases (e.g. employers, police, employment restriction schemes) were given for different purposes and not for research. However, as far as possible, documentary evidence was validated by cross-referencing to other sources, interpretations were tested across a range of evidence and compared across cases.

Findings were analysed using a combination of summarising the prevalence of codes and discussing similarities and differences in related codes and categories with reference to previous research findings. Detailed notes and direct examples of text found in the data were recorded to provide deeper description and examples of meaning.

As the only empirically grounded micro-level theory outlining the offence process of FSOs and as a model highly relevant to the aims of the research, the Descriptive Model of Female Sexual Offending (DMFSO) (Gannon et al., 2008) was used to support the analysis of the case material offering the ability to consider a wide range of abuser characteristics as well as to compare findings with the research conducted by Gannon et al. (2008; 2010). This comparison was helpful in terms of approaches to abuse demonstrated by a general FSO population, however, the comparative results should be considered in light of the fact that their sample was larger (22), it was made up of convicted offenders exclusively, it included those who had offended against adults as well as children, and it included a wider range of offender types. The DMFSO includes three phases: Background factors; Pre-Offence Period and the Offence, and Post Offence Period. The findings were compared primarily to the pre-offence and offence periods due to the lack of data in relation to the subjects' early life history and background in most cases and the research project time restrictions limiting full consideration of the post offence period. 
The reliance on analysis and interpretation of prerecorded written material rather than first hand interviews meant there were some limitations on the extent to which this would help determine why such abuse occurs. There are many factors that could have influenced the way information was recorded and reported in the documentation used in the study. However, the benefit of the use of paper records constituting the case file data was the ability to carefully ascertain the validity of the FCSAs' own responses and descriptions of events through cross comparison with additional evidence from a range of other sources. Being restricted to the interpretation of pre-recorded material also meant there was no option to clarify or test any interpretations or contradictions with the subjects directly. For the most part the researchers were reliant on their own interpretations (or those of others). Much of material used was gathered during the post-abuse phase, furthermore only a small number of the subjects had undergone any known therapy exploring in any more depth the reasons for their behaviour. Some of the data, though certainly not all of it, related to those self-reports the FCSAs made in their explanations to employers, the police or the safeguarding schemes for the purpose of avoiding future sanctions for their conduct, therefore there is the increased likelihood that their full honesty would be compromised. This was not always the case, however, as a small number of responses were obtained in the therapeutic context where there was less likelihood of future punishment and, therefore, the subjects were likely to have been more open and honest. There was also extremely useful contemporaneous data generated in the period leading up to and during the abusive behaviour (such as letters, social media exchanges and diary extracts) created by the abuser allowing a very effective, uninhibited insight in to their thinking and behaviour at the time.

\section{FINDINGS}

\section{Characteristics and Typologies}

When considering the characteristics and etiology of female sexual offenders the findings in the existing research literature tend to agree that: most are aged between 16 and 36 years old; most fall into low and middle range in terms of socio-economic status; many lack social skills, have low self-esteem and experience difficulty in relationships (see, for example, Brayford 2012).

The mean age of the sample in our study was 35 with a range from 26-44 years, which higher than that found in previous studies. It could have been argued that these types of relationships would be more common among the youngest child care professionals (early in their careers) of a similar age to the adolescents but this was not found to be the case. All of the women were considered to fall into the middle range of socio-economic status, again probably linked to their professional jobs. There did not appear to be any particular social skills deficits for any of these women, indeed most of them were perceived to be very successful in their working relationships with colleagues and most appeared to have friendship groups of their own, although three did suffer impoverished social support, due to living and working in an area new to them and away from their childhood homes and extended families. Low self-esteem was an evident feature for $40 \%$ of the women and this was also coupled with loneliness and feelings of isolation from others. In a number of cases there was insufficient evidence to make a reasoned conclusion about selfesteem issues although these might have been inferred. Relationship difficulties were a dominant feature for $80 \%$ of the women in the pre-offence period with four exhibiting a life history of negative personal relationships and three showing evidence of extreme partner dependency. This manifested itself in significant dependency on the adolescents for their own happiness.

There are a number of common features of abusers who target adolescent males. These are: victim elevation to adult status with the abuser failing to see their behaviour as criminal or abusive; the victim being seen as a willing participant in a consensual relationship; the abusers typically acting from a position of power, and the initial sexual encounter being often not pre-meditated, but later may become the result of calculation and planning (Harris, 2010). This type of abuser is also less likely to have been victimised sexually as a child according to a clinical study (Saradjian, 1997). Abusers do tend to have experienced verbal or emotional abuse in their childhood and may have had a distant or absent father (Harris, 2010). FCSOs' own previous experience of child sexual abuse or sexual abuse as an adult has been a common feature in previous studies (Jennings, 1993; Johansson-Love et al., 2009, Wijkman et al., 2010; Gannon et al., 2008). Although in most cases in our study there was insufficient information about the subject's early development, only one of the women in this study had disclosed childhood sexual abuse. There was no clear evidence of sexual abuse as adults 
although two of the women generally referred to having previously been in 'abusive' relationships without clarifying the nature of that abuse. Most of the abusers in our study considered the victim a willing participant, an equal, with a few clearly not understanding the impact the position of trust had, even after the abuse was exposed and they were challenged about it. $60 \%$ did not appear to accept that the child was harmed by the relationship only by the aftermath when it was discovered. There was clear evidence of cognitive distortions in all of the women by either minimising the harm or attempting to justify the abuse.

Questioning the helpfulness of previous typologies based on perpetrator characteristics in fully understanding FSOs, Gannon et al. (2008) suggested that a more appropriate approach is to consider the vulnerability factors being identified in those females who have sexually abused children those being: mental health problems; cognitions and empathy; deviant sexual interest; intimacy and social deficits; dependency issues and emotional self-management problems.

There are discrepancies in the existing literature about the impact of mental health on FCSOs (Johansson-Love et al., 2008; Wijkman et al., 2010). Mental health issues were a feature for $40 \%$ of the women in our study. Three appeared to be suffering from stress/depression around the time of the abuse and one appeared to suffer from severe psychological disturbance. Of these, one had previously attempted suicide and three had expressed suicidal thoughts in the pre-offence and offence period. Concern for the mental well-being of the perpetrator was actually expressed by the victims in a few cases. In one case the victim and his family did not pursue police action being concerned for the abuser's mental state. Implicit and explicit threats to harm herself were made by two of women to their victims, placing them under significant emotional pressure.

Substance abuse has been found to be a risk factor in FCSOs (Johansson-Love et al., 2006), however, Johansson-Love et al. (2009) found that FSOs showed the lowest level of alcohol abuse when compared to MSOs and violent offenders. The case file evidence in our sample did not reflect extensive substance abuse in many of the FCSAs and drug use was not apparent in any of the cases. Three women did appear to be drinking fairly regularly or excessively around the time of the abusive behaviour but equally there was no evidence of this in the remainder of cases. Two women appeared to be using alcohol as a way to cope with their problems and feelings in general. In three cases drinking alcohol in the presence of the victim or even along with them was a feature, despite the fact all victims were under legal drinking age. It is believed that this demonstrated implicit planning to some extent where alcohol was a dis-inhibitor. A number of abusers also regularly commented on their alcohol consumption when communicating with the victim in their absence. This is perhaps reflective of the perpetrator's desire to appeal to the adolescent demonstrating the type of behaviour they perhaps thought would impress the victim or would be expected behaviour of the victim and their peer group.

Chaotic, abusive backgrounds have also been evident in FSO's in general (Matthews 1993). Again the evidence relating to full background history of most cases was unavailable in our study, but where it was available or where more recent lifestyle information prior to the abusive behaviour was evident, it did not appear to be a significant factor. Many of the women had stable employment histories, were considered to be reliable and committed employees and colleagues and only two had any previous criminal record (both for motoring offences).

Matthews (1993) found that social relationship problems were prevalent in FSOs who were often friendless and willing to do almost anything for acceptance. However, in this current study there was only an apparent lack of age-appropriate friendships and social support for three women. This was caused by moving to a new area, living/working in an independent or boarding school environment or working very long hours limiting the opportunity to engage with adults and resulting in social time spent in the environment with children. This also manifested itself in feelings of loneliness, isolation and separation from others.

Negative relationships with men (showing extreme dependency or rejection) have been identified as another risk factor for FSOs (Jennings, 1993; Gannon et al., 2008) and in this study eight women had experienced notably negative relationships with domestic partners. There was evidence of previous domestic abuse in two cases and most of the women were evidently experiencing difficulties in their personal relationships in the pre-offence and offence periods. What was particularly notable about these cases was that seven were involved in long term partnerships at the time of the abuse and five were fully prepared to 
leave (or had indeed left) their partners to pursue a relationship with the child. They were also prepared to give up their jobs and in one case their own family and children too. Four women continued to pursue the relationship after the formal position of trust relationship ended. These short and longer term relationship difficulties appear to be manifested in low self-esteem, severe passivity and dependency in the sample subjects. Low self-esteem along with feelings of inadequacy and vulnerability were fairly common. Three women demonstrated extreme dependency on the child for their happiness and well-being as discussed above. Faller reported that independent FCSOs used their victims for emotional and sexual gratification (cited in Johansson-Love et al., 2008) and in this study almost all the women were evidently seeking substitute gratification with the child. Emotional gratification appeared to be most common (evident in seven cases; three as the only established motivation, three as primary motivation and one as a secondary motivator), with sexual gratification only or primarily sought in two cases and as a secondary motivation in three cases.

In order to meet these needs and justify the abusive behaviour or lower inhibitions cognitive problems were a feature in all cases. Beech et al's 2009 study (cited in Harris 2010) identified a number of cognitive distortions in FSOs: the perception that children are sexual objects, seductive or sexually excited; that victims are not harmed by the behaviour; the general view that the world is uncontrollable and things just happen and the perception of a 'dangerous world' where it is preferable to engage in relationships with children. There was ample evidence of faulty thinking in this current study with all women demonstrating cognitive problems in some form or another ranging over:

victim blaming;

belief of a genuine relationship;

seeing the child as an equal, and other young people as genuine friends;

belief that the behaviour was not harmful or abusive.

There was also evidence of three women clearly externalising blame for the behaviour (e.g. blaming their employer for not recognising their stress, blaming the boarding school environment) and five clearly minimising the impact of the abuse and their accountability for it. An identified difference between
FCSOs and MCSOs is their respective cognitions about the child victim. Females have been found to construct perceptions and beliefs about the child (positive or negative) and will interpret the child's behaviour to validate this perception (Saradjian, 1997). For those who target young children this tends to be a negative construction and for those who abuse adolescents this is usually a positive one (Hunt 2006). The findings from our study also show this to be the case. In all cases the construction of the adolescent victim was a positive one, with a number of women almost idolising the child and failing to recognise any faults or weaknesses in them despite any evidence to the contrary.

Emotional self-management problems were evident to some extent in most of the women. Infatuation was a common theme in the cases studied as was over emotional involvement with the child. There was frequent evidence of the abusers trying to deal with the child's problems, becoming over-involved emotionally which then lead to them feeling unable or unwilling to 'abandon' the child and developing into an inappropriate abuse of trust relationship. Given the extent of infatuation and their willingness to give up their existing jobs, partnerships and in some cases their families and geographical location many of the women did not seem to see the inherent difficulties in pursuing a long term relationship, the problems the substantial age gap and life circumstance differences that might be likely to inhibit a long term successful relationship. For some, their personal emotional sadness and low self-esteem or feelings of vulnerability led to them finding happiness in the contact with the child and they were unable to resist from it, even when they knew it was problematic. Low self-control was apparent in these situations.

It is worth noting that previous typologies of FCSOs do not appear to specifically account for women who abuse adolescent females. Three cases in this study were such abusers, however, when comparing the findings there did not appear to be any marked difference in the motivations or approach to the abuse between those who abused adolescent females versus males. What was notable was that two of the three women who had abused adolescent females had never had any previous homosexual relationships. They appeared to be quite intrigued by the homosexuality of the female adolescent and drawn into exploring their own sexuality through the abusive relationship. 


\section{Descriptive Model of Female Sexual Offending}

As discussed, a lack of data in relation to the subjects' early life history and background in most cases meant the model's 'Background Factors' were unable to be fully considered. Nonetheless, evidence and information gathered in relation to the Background Factors (where available) and Pre-Offence Period phases of the model were helpful in identifying etiological factors of relevance in each case to help answer the research question of 'why' females engage in abuse of trust behaviours. Vulnerability factors in some cases become further entrenched into risk factors as a result of an unstable lifestyle in the months preceding placing the female at a higher risk of abusive behaviour. In our study there was more information available about situational factors than background factors so this allowed for a better analysis of the preoffending period. The Pre-Offence Period phase of the model looks at the period preceding the abusive behaviour, from around 12 months earlier until immediately prior. A common pattern in Gannon et al.'s (2008) sample of general FSOs was feelings of isolation and lack of social support following personal relationship difficulties or major life stressors ( $n=14$ out of $22 ; 64 \%$ ). In our study these risk factors were also evident in most cases. $70 \%(n=7)$ reported personal relationship problems in this period and examples of the other kinds of major life stressors experienced were financial problems, infertility, moving to live in a new area and having a child. Gannon et al. (2008) found that other women demonstrated maladaptive coping strategies involving severe substance misuse and passive coping. Although there was insufficient evidence in the case files to determine severe substance abuse, three women in the current study appeared to be using alcohol regularly and potentially to excess in this period and two appeared to be using alcohol as a way to cope with their problems and feelings in general. There was an apparent lack of age appropriate friendships and social support for three women. This was caused by moving to a new area, living/working in an independent or boarding school environment or working very long hours limiting the opportunity to engage with adults, and resulting in social time spent in the environment with children. This also manifested itself in feelings of loneliness, isolation and separation from others.

Around six months prior to the abuse all of the FSOs in Gannon et al's (2008) study had unstable lifestyles characterised by domestic disturbances, life deterioration, multiple caregiver responsibilities, financial difficulties, criminal activity and associated general negative affect. This appears to be true in this study also as all of the women showed evidence of unstable lifestyle in that period with relationship problems being the most prevalent. Over-work, often apparently driven by a desire to escape an unhappy personal life or to spend time with children to meet social and intimacy needs, was the second most prominent type of instability evident in $40 \%$ of the women. Interestingly, only one woman in our study had engaged in any criminal activity during the period examined.

According to Gannon et al. (2008), unstable lifestyle generated the formulation of goals to abuse in the women in their study. This Goal Establishment stage occurs around the unstable lifestyle stage or immediately after it. The authors determined that the women in their study were motivated by either sexual gratification $(n=6 ; 27 \%)$; intimacy $(n=5 ; 23 \%)$ or instrumental/other motivations such as revenge or humiliation $(n=3 ; 14 \%)$. In our study the determination of an abuser's motivation had to be inferred from all available information rather than a direct response during interview. However, there were numerous examples of comments or statements by the FCSAs suggesting their motivation for the abusive behaviour. Intimacy was the most prevalent goal in this sample $(n=7 ; 70 \%)$. They also found that lone offenders tended to value intimacy which is consistent with the prevalence in this study involving lone abusers exclusively. Sexual gratification was an apparent goal in five cases (either as a primary or secondary goal) in the current sample where the women's cognitions reflected their consideration that the victim was an 'equivalent adult' and 'sexually aware'. There was no evidence of instrumental/other motivations for the abuse found in this sample.

\section{DISCUSSION / CONCLUSION}

Primarily as a result of public attention in news and entertainment media there has been evidence of increasing awareness of female perpetrated child sexual abuse over the past decade or so along with emerging recognition of the specific issue of females who engage in abuse of trust behaviours with adolescents. It could be that this increased awareness has contributed to the dramatic increase in children counselled by ChildLine about sexual abuse by females during the last decade as well as the comparatively much higher proportion of FCSOs being convicted or cautioned for abuse of trust offences than 
MCSOs. There is no clear evidence to suggest that the actual prevalence of female child sexual abuse is increasing as such (although the difficulties of ascertaining these rates have been shown to be problematic). Therefore, it is possible that the increase in numbers is the result of victims feeling more able to disclose the abuse and professionals in organisations as well as within the child protection and criminal justice systems being more alert to the signs of such abuse. Despite the trend however, the sense prevails that so much abuse of this nature remains undisclosed for a range of reasons including the impact of cultural norms and gender representations.

Through a qualitative analysis of a small sample of case studies our research explored a unique area of female child sexual abuse helping to address apparent gaps in knowledge not only around those women who abuse adolescents (both male and female) but also those who do so in the course of their employment. In doing so the aim is to help increase public and professional awareness of this specific type of abusive behaviour particularly with regard to helping employers/carers to identify early indicators of inappropriate behaviour as well as potential vulnerability and risk factors in females working with children to help prevent further harm to young victims. Increased awareness may also in turn assist in improving child protection policies and procedures in organisations and open up the discussion about the realities of female perpetrated abuse of trust thereby further addressing any cultural or professional denial of the problem.

This study explored why the women in the case studies have engaged in abuse of trust behaviours and compared these with factors considered of etiological importance in FCSOs and FSOs in general, and existing theoretical frameworks. In doing so it appears that the females in this sample engaged in abuse of trust behaviours for a variety of reasons. Some of the factors of etiological significance in females who engage in abuse of trust behaviours are common to those found in FSOs and FCSOs in general, such as unstable lifestyles, low self-esteem, relationship difficulties and emotional self-management problems. Differences related to lower levels of substance abuse, a higher age range and socio-economic status, less prevalence of severe social skills deficits and to some extent chaotic and abusive backgrounds in this subject group. Where there are differences, they appear to be explained in part by the specific employment type, suitability factors for those employed in this type of work and the specific typology characteristics of those who abuse adolescents rather than wider sample groups covered in other research. Similarities with male professional perpetrators appeared to relate to being older, with higher IQ, less problematic personal experiences in their own backgrounds and less previous convictions (sexual and non-sexual). Like professional perpetrators the women in this study demonstrated high levels of emotional overidentification with children, and generally lower levels of distorted sexual attitudes and empathy distortions. Consideration of the specific reasons why women engaged in this type of abuse found a number of key vulnerability factors for this subject group with personal relationship difficulties, problems with self-esteem and cognitive distortions being the most prevalent. Motivations appear to have been primarily driven by intimacy needs rather than any particular sexual deviancy. The abusers themselves tended to explain their behaviour as resulting from a genuine romantic and emotional relationship with the adolescent. Most failed to recognise or accept the impact of the position of trust and all demonstrated a range of cognitive distortions contributing to the occurrence of the abuse in the first place and its continuation thereafter.

Commonalities between the abusers in the sample were particularly noticeable in the pre-offence period. All of the women had unstable lifestyles in this period most commonly as a result of relationship problems but other life stressors such as financial difficulties, work or living environment changes were also evident. These lifestyle problems tended to lead to feelings of isolation and unhappiness, sometimes resulting in stress or depression. The women then demonstrated maladaptive coping strategies such as alcohol use (also acting as a dis-inhibitor) and over-engagement at work, but most often turning to adolescents for emotional and sexual gratification as a substitute. They relied upon young people as a significant source of social interaction, either because they were lacking social and emotional support from their partners or friends or because they were overly consumed by work activities which brought them into more regular contact with adolescents limiting their opportunities for their own social life outside of the workplace. These emotional self-management difficulties coupled with high levels of cognitive distortions about the impact on the adolescent and a failure to recognise the inherent inequality of their position of trust resulted in the FCSAs engaging in abuse of trust relationships. Almost all the women appeared to consider the adolescent as 
an equal partner in the 'relationship', failing to recognise the abuse of their position of trust. For many of the women the intensity of their feelings and attraction to the child combined with general problems in their own lives, both in the longer and shorter term, led to their engagement in abuse of trust behaviours.

Interestingly there was no apparent difference in the motivations and reasons for the abuse between those who abused males and those who abused females, although curiosity about the adolescents' sexuality and a desire to explore their own sexuality did appear to be one additional factor contributing to the abuse in two of the cases involving adolescent females.

Overall the results show that all of the females who abused whilst in positions of trust in this study generally followed Gannon et al's (2008) Descriptive Model of Female Sexual Offending in the pre-offence and offence stages. The study subjects aligned to the Implicit Disorganised pathway (Gannon et al., 2010), meaning that they did not initially appear to intend to offend but that they failed to regulate their behaviour to meet their own intimacy needs. Furthermore, they all aligned with the maternal approach category in terms of their overall abuse approach. This finding, referring to the non-aggressive manner of the approach to the abuse, is not surprising given it has been shown to be common in lone abusers and particularly those who abused teenage boys (see Gannon et al., 2008; Harris, 2010).

The authors of the current article are aware of the potential for the professional experience of the first author (who examined the case files) to have influenced interpretation of codes and meaning in the written material examined. This would have been more effectively addressed had it been possible to both authors to work alongside each other during the first analysis of cases with inter-rater reliability strengthening any interpretation. It is also acknowledged that one of the cases used in the sample was one previously well known to the first author. As far as possible this researcher was careful to re-examine the evidence objectively and in comparison to the other sample cases without being unfairly influenced by their earlier thinking and decision making on the case. However, this case was a particularly useful one in terms of the richness of the data and the fact it was one of very few where the victim was an adolescent female and, therefore, was considered valid and useful in attempting to address the research questions. The research findings would also have been more robust in determining the specific factors applicable to those females who abuse whilst in positions of trust had comparative control groups been used. Unfortunately time limitations on the study did not allow for this.

Despite the limitations, the study appears to be unique in: (a) exploring females who engage in abuse of trust behaviours specifically; (b) considering those who have abused adolescent females which appear to be missing from other studies and typological development; (c) considering cases arising from the employment and safeguarding environment as opposed to the criminal justice system or clinical situations dominant in most other studies and providing further validation of the DMFSO in relation to the preoffence and offence phases of the model. The research also included the analysis of extremely valuable data such as diary extracts, letters and social media exchanges produced by the abusers during the period of the abusive behaviour which can be more helpful in identifying particular motivations and cognitive distortions contemporaneously rather than solely relying on post-event explanations provided by the abuser himself/herself.

Overall, it is hoped that this study has furthered knowledge about why females engage in abuse of trust behaviours. By better understanding the motivations of such female abusers and the circumstances surrounding their engagement in this abusive behaviour we can better educate parents, carers and employers to be alert to, and recognise potential signs of abuse of trust relationships.

\section{ACKNOWLEDGEMENT}

This study was supported by the Disclosure and Barring Service (DBS), UK and we extend our thanks to the DBS Senior Management Team for allowing use of the data that made this study possible and their support during the research process.

\section{REFERENCES}

Arber, S. 2001. 'Designing Samples', pp 58-71, in Gilbert, N. (ed.) Researching Social Life, London: Sage

Ashfield, S. 2011. Female Sexual Abusers- Facts and Fiction. Lucy Faithfull Foundation. Accessed via: http://thamesvalleypartnership.org.uk/wp-content/uploads/female-sexualabusers-facts-and-fiction1.pdf [accessed 3 October 2012]

Beech, A.R., Parrett, N., Ward, T., \& Fisher, D. 2009. "Assessing female sexual offenders' motivations and cognitions: An exploratory study". Psychology, Crime and Law, 15: 201-216. http://dx.doi.org/10.1080/10683160802190921 
Bichard, M. 2004. The Bichard Inquiry Report. An independent inquiry arising from the Soham murders. London: The Stationery Office.

Brayford, J. 2012. 'Female sexual offending: An impermissible crime'. Crime Prevention and Community Safety, 14: 212-224. http://dx.doi.org/10.1057/cpcs.2012.5

Bunting, L. 2007. 'Dealing with a Problem That Doesn't Exist? Professional Responses to Female Perpetrated Child Sexual Abuse', Child Abuse Review, 16: 252-267 http://dx.doi.org/10.1002/car.982

Bunting, L. 2005. Females who Sexually Offend against Children: Responses of Child Protection and Criminal Justice Systems. London: NSPCC

Child Protection in Sport Unit. 2011. Briefing: Abuse of Trust in Sport. London: Child Protection in Sport Unit

Crown Prosecution Service. 2013. Freedom of Information Request Ref: 4043, 29 July 2013.

Denov, M.S. 2004a. 'The Long-Term Effects of Child Sexual Abuse by Female Perpetrators'. Journal of Interpersonal Violence, $19,1137-1156$ http://dx.doi.org/10.1177/0886260504269093

Denov, M. 2004b. Perspectives on Female Sexual Offending: A Culture of Denial. Aldershot: Ashgate

Erooga, M. 2009 Towards Safer organisations: Adults who Pose a Risk to Children in the Workplace and Implications for Recruitment and Selection. London: NSPCC.

Elliott, M. 1993. Female Sexual Abuse of Children. London: The Guildford Press

Finkelhor, D. 1986. A Sourcebook on Child Sexual Abuse. London: Sage

Finkelhor, D. \& Williams, L. 1988. Nursery Crimes: Sexual Abuse in Day Care. London: Sage

Flick, U. 2009. An Introduction to Qualitative Research. $4^{\text {th }}$ edition London: Sage

Freel, M. 1995. Women who Sexually Abuse Children. Norwich: Social Work Monographs

Gannon, T.A. and Alleyne, E. 2013. 'Female Sexual Abusers' Cognition: A Systematic Review'. Trauma Violence Abuse, 14: $67-79$ http://dx.doi.org/10.1177/1524838012462245

Gannon, T.A. and Cortoni, F. (Eds) 2010. Female Sexual Offenders: Theory, Assessment and Treatment. Chichester: WileyBlackwell http://dx.doi.org/10.1002/9780470666715

Gannon T.A., Rose M.R. \& Ward, T. 2008a. 'Female child sexual offenders: Towards integrating theory and practice'. Aggression and Violent Behaviour, 13: 442-461 http://dx.doi.org/10.1016/j.avb.2008.07.002

Gannon, T.A, Rose, M.R. and Ward T. 2008b. 'A Descriptive Model of the Offense Process for Female Sexual Offenders'. Sex Abuse, 20: 352-374

Gannon, T.A., Rose, M.R and Ward, T. 2010 'Pathways to Female Sexual Offending: Approach or Avoidance?'. Psychology, Crime \& Law, 16(5): 359-380 http://dx.doi.org/10.1080/10683160902754956

Gartner, R. 2005. Beyond Betrayal: Taking Charge of Your Life after Boyhood Sexual Abuse. London: Wiley

Grubin, D. 1998. Sex Offending against Children: Understanding the Risk. London: Policing and Reducing Crime Unit.

HM Government. 2013. Working Together to Safeguard Children: A Guide to Inter-Agency Working to Safeguard and Promote the Welfare of Children. London: Home Office

Hetherton, J. \& Beardsall, L. 1998. 'Decisions and Attitudes Concerning Child Sexual Abuse: Does the gender of the perpetrator make a difference to child protection professionals?'. Child Abuse and Neglect, 22(12): 1265-1283 http://dx.doi.org/10.1016/S0145-2134(98)00101-X
Home Office. 2003. Caring for Young People and the Vulnerable: Guidance for Preventing Abuse of Trust. London: Home Office

Home Office. 2007. The Review of the Protection of Children from Sex Offenders. London: Home Office

Hislop, J. 2001. Female Sex Offenders. Ravensdale: Issues Press

Hunt, L. 2006. Females who Sexually Abuse Working in Organisations with Children. Sydney: Child Wise Australia

Jennings, K. 1993. 'Female Child Molesters: A Review of the Literature'. Pp.241-257 in Elliott, M. (ed.). Female Sexual Abuse of Children. London: The Guildford Press.

Johansson-Love, J. and Fremouw, W. 2009. 'Female Sex Offenders: A Controlled Comparison of Offender and Victim/Crime Characteristics', Journal of Family Violence, 24: 367-376 http://dx.doi.org/10.1007/s10896-009-9236-5

Johansson-Love, J. and Fremouw, W. 2006. 'A Critique of the Female Sexual Perpetrator Research'. Aggression and Violent Behaviour, 11(1): 12-26 http://dx.doi.org/10.1016/i.avb.2005.05.001

Kaufman, K., Wallace, A.M., Johnson, C.F \& Reeder, M.L. 1995 'Comparing female and male perpetrators' modus operandi: Victim's reports of sexual abuse'. Journal of Interpersonal Violence, 10(3): 322-333 http://dx.doi.org/10.1177/088626095010003006

Kite, D. \& Tyson, G.A. 2004. 'The impact of perpetrator gender on male and female police officers' perceptions of child sexual abuse'. Psychiatry, Psychology \& Law, 11(2): 308-318 http://dx.doi.org/10.1375/pplt.2004.11.2.308

Lawson, L. \& Rowe, S. 2010. Treatment of females convicted of molesting children'. Journal of Forensic Nursing, 6(4): 180-7 http://dx.doi.org/10.1111/j.1939-3938.2010.01086.x

Matthews, J (1993) 'Working with female sexual abusers'. Pp.57-73 in Elliott, M. (ed.), Female Sexual Abuse of Children. London: The Guildford Press

Matravers, A. (Ed). 2005. Sex Offenders in the Community: Managing and reducing the risks. Cullompton: Willan

McKeown, A. 2010. 'Female Offenders: Assessment of risk in forensic settings', Aggression and Violent Behaviour, 15: 422-429 http://dx.doi.org/10.1016/j.avb.2010.07.004

Mellor, D. and Deering, R. 2010. 'Professional response and attitudes toward female-perpetrated child sexual abuse: a study of psychologists, psychiatrists, probationary psychologists and child protection workers'. Psychology, Crime \& Law, 16(5): 415-438 http://dx.doi.org/10.1080/10683160902776850

Ministry of Justice. 2011. Offender Management Statistics Quarterly Bulletin April-June 2011 England and Wales. London: Ministry of Justice

Ministry of Justice, Personal Correspondence, Response to Freedom of Information access request, 26 June 2013 (FOI Ref 38383039)

Moulden, H.M., Firestone, P., Kingston, D. and Wexler, A. 2010. 'A Description of Sexual Offending Committed by Canadian Teachers'. Journal of Child Sexual Abuse. 19: 403-418 http://dx.doi.org/10.1080/10538712.2010.495046

Nelson, E.D. 1994. 'Females Who Sexually Abuse Children: A Discussion of the Gender Stereotypes and Symbolic Assailants'. Qualitative Sociology, 17(1): 63-88 http://dx.doi.org/10.1007/BF02393546

NSPCC. 2010. ChildLine Casenotes: Children Talking to ChildLine about Sexual Abuse. London: NSPCC

NSPCC. 2011. Child Abuse and Neglect in the UK Today. London: NSPCC

Rudin, M., Zalewski, C., \& Bodmer-Turner, J. 1995. 'Characteristics of child sexual abuse according to perpetrator gender'. Child Abuse and Neglect, 17(8): 963-973 http://dx.doi.org/10.1016/0145-2134(95)00058-G 
Sandler, J. and Freeman, N. 2011. 'Female sex offenders and the criminal justice system: A comparison of arrests and outcomes'. Journal of Sexual Aggression, 17(1): 61-76 http://dx.doi.org/10.1080/13552600.2010.537380

Sandler, J. and Freeman, N. 2007. 'Topology of Female Sex Offenders: A Test of Vandiver and Kercher'. Sex Abuse, 19: 73-89

Saradjian, J. 2010. 'Understanding the Prevalence of FemalePerpetrated Sexual Abuse and the Impact of that Abuse on Victims'. Pp.9-30 in Gannon, T.A and Cortoni, F (Eds) 2010. Female Sexual Offenders: Theory, Assessment and Treatment. Chichester: Wiley-Blackwell

Saradjian, J. 1997. Women Who Sexually Abuse Children: From Research to Clinical Practice. Chichester: Wiley

Silverman, D. 2010. Doing qualitative research: a practical handbook. $3^{\text {rd }}$ edition. London: Sage

Sullivan, J., Beech, A., Craig, L. and Gannon, T.A. 2010. 'Comparing Intra-Familial and Extra-Familial Child Sexual Abusers with Professionals who have Sexually Abused Children with whom they Work'. International Journal of Offender Therapy and Comparative Criminology, 55(1): 56-74 http://dx.doi.org/10.1177/0306624X09359194

Sullivan, J. and Beech, A. (2004) 'A comparative study of demographic data relating to intra- and extra-familial child sexual abusers and professional perpetrators'. Journal of Sexual Aggression, 10(1): 39-50 http://dx.doi.org/10.1080/13552600410001667788

Sullivan, J. and Beech, A. 2002. 'Professional Perpetrators: Sex Offenders Who Use Their Employment to Target and Sexually Abuse the Children With Whom They Work'. Child Abuse Review, 11: 153-167 http://dx.doi.org/10.1002/car.737
Toner, K. 2010. A Briefing Paper on Abuse of Trust in Sport. Belfast: NSPCC Northern Ireland

Townsend, M. and Syal, R. 2009. 'Up to 64,000 women in UK 'are child-sex offenders". The Observer, Sunday 4 October 2009, <http://www.guardian.co.uk/society/2009/oct/04/uk-femalechild-sex-offenders> [accessed on 3 January 2012]

Vandiver, D. and Kercher, G. 2004. 'Offender and Victim Characteristics of Registered Female Sexual Offenders in Texas: A Proposed Typology of Female Sexual Offenders'. Sex Abuse, 16: 121-137

Vandiver, D. and Walker, J. 2002. 'Female Sex Offenders: An Overview and Analysis of 40 Cases'. Criminal Justice Review, 27(2): 284-299 http://dx.doi.org/10.1177/073401680202700205

Warner, N. 1992. Choosing with Care. The Report of the Committee of Inquiry into the Selection, Development and Management of Staff in Children's Homes. London: HMSO

Whetsall-Mitchell, J., \& Morse, J. 1998. From victims to survivors: Reclaimed voices of women sexually abused in childhood by females. Washington DC: Taylor and Francis

Wijkman, M., Bijleveld, C. and Hendriks, J. 2011. 'Female Sex Offenders: Specialists, Generalists and Once-Only Offenders'. Journal of Sexual Aggression, 17(1): 34-45 http://dx.doi.org/10.1080/13552600.2010.540679

Wijkman, M., Bijleveld, C. and Hendriks, J. 2010. 'Women Don't Do Such Things! Characteristics of Female Sex Offenders and Offender Types'. Sex Abuse, 22: 135-156

Young, V. 1993. 'Women Abusers - A Feminist View'. in Elliott, M. (ed) 1993. Female Sexual Abuse of Children. London: The Guildford Press

\section{DOl: http://dx.doi.org/10.6000/1929-4409.2013.02.47}

(C) 2013 Darling and Antonopoulos; Licensee Lifescience Global.

This is an open access article licensed under the terms of the Creative Commons Attribution Non-Commercial License (http://creativecommons.org/licenses/by-nc/3.0/) which permits unrestricted, non-commercial use, distribution and reproduction in any medium, provided the work is properly cited. 